\title{
Editorial: "Recent advances in gamma/delta T cell biology: new ligands, new functions, and new translational perspectives"
}

\author{
Dieter Kabelitz ${ }^{1 *}$ and Julie Déchanet-Merville ${ }^{2}$ \\ ${ }^{1}$ Institute of Immunology, University of Kiel, Kiel, Germany, ${ }^{2}$ CNRS UMR 5164, Université de Bordeaux, Bordeaux, France
}

Keywords: $\gamma \delta$ T cells, infection, tumor immunity, phosphoantigen, IL-17

Since their discovery in the mid-1980s, interest in the immunological significance of $\gamma \delta \mathrm{T}$ cells has been subject to oscillations. The initial excitement over the unexpected discovery of a second $\mathrm{T}$ cell receptor (TCR) was followed by years of uncertainty as to the biological importance of these ambivalent T cells. Major breakthroughs led to the identification of specific and unique antigens for the $\gamma \delta$ TCR and accumulating evidence now shows that $\gamma \delta$ T cells play a major role in local immunosurveillance, thereby controlling tumorigenesis. Since 2004, biannual international $\gamma \delta \mathrm{T}$ cell conferences are held to bring together experts in basic and clinical $\gamma \delta \mathrm{T}$ cell research. To make accessible and synthesize the body of knowledge that has been put together, to date, we have organized a "Research Topic" on $\gamma \delta$ T cells consisting of a collection of original articles and focused reviews written by leading experts in the field. The idea of this Research Focus was to present the current status and "hot topics" as well as clinical perspectives on $\gamma \delta$ T cell research.

\section{OPEN ACCESS}

Edited by:

Rene De Waal Malefyt,

Merck Research Laboratories, USA

Reviewed by:

Luis Alejandro Zuniga,

Merck Research Laboratories, USA

${ }^{*}$ Correspondence:

Dieter Kabelitz

dietrich.kabelitz@uksh.de

Specialty section:

This article was submitted to T Cell Biology, a section of the journal

Frontiers in Immunology

Received: 09 May 2015

Accepted: 06 July 2015

Published: 21 July 2015

Citation:

Kabelitz $D$ and Déchanet-Merville J (2015) Editorial: "Recent advances in gamma/delta T cell biology: new ligands, new functions, and new

translational perspectives".

Front. Immunol. 6:371.

doi: 10.3389/fimmu.2015.00371

\section{$\gamma \delta$ T Cells: Differentiation, Activation, and Signaling}

The signaling pathways governing $\gamma \delta \mathrm{T}$ cell differentiation and activation have been discussed in contributions from Carl Wares's (1) and Bruno Silva-Santos's (2) groups. Ribeiro et al. discuss the control of $\gamma \delta \mathrm{T}$ cell activation and differentiation by distinct classes of cell surface receptors, namely (i) the TCR, (ii) costimulatory receptors (with a focus on CD27), (iii) cytokine receptors, (iv) NK receptors, and (v) inhibitory receptors. They further summarize how activation of $\gamma \delta \mathrm{T}$ cells can be controlled by the TCR as well as by activating NK receptors. To terminate $\gamma \delta \mathrm{T}$ cell responses, several inhibitory receptors can deliver negative signals, notably $\mathrm{PD}-1$ and $\mathrm{B}$ - and Tlymphocyte attenuator (BTLA) (2). Bekiaris et al. focus on the cytokine control of innate $\gamma \delta \mathrm{T}$ cells, and discuss the role of IL-7 in being critical for thymic development of $\gamma \delta$ T cells by regulating the survival of progenitor cells and inducing $\mathrm{V}(\mathrm{D}) \mathrm{J}$ recombination within the TCR $\gamma$ gene locus. IL-7 also supports homeostatic proliferation of $\gamma \delta$ T cells and regulates surface expression of BTLA in a STAT5-dependent manner (1).

In recent years, IL-17 has been identified as an essential cytokine that regulates the recruitment of neutrophils during an inflammatory response. IL-17 must be rapidly available in an acute infection. $\alpha \beta$ T cells producing IL-17 (Th17 cells) require specific antigenic stimulation and an appropriate cytokine milieu for differentiation. $\gamma \delta$ T cells have been identified as an important "innate" source of rapid initial IL-17 production, which is thought to occur without specific TCR triggering (3). Several years ago, the group of Immo Prinz generated a unique mouse model to monitor early steps of $\gamma \delta \mathrm{T}$ cell development (4). Using these reporter mice, they demonstrated that IL-17 producing $\gamma \delta$ T cells develop during the embryonic period and persist in adult mice as self-renewing, longlived cells (5). Interestingly, Wei and colleagues have provided evidence that the TCR repertoire of such naturally occurring IL-17-producing murine $\gamma \delta \mathrm{T}$ cells is highly restricted, with little 
or no junctional diversity, regardless of their anatomical origin. These findings strongly suggest that antigen recognition is involved in the establishment and/or function of such "innate" IL17 producing $\gamma \delta$ T cells (6). Further aspects of IL-17 producing $\gamma \delta$ T cells, also addressing their role in various pathophysiological conditions, are discussed in the review article by Patil et al. (7).

In addition to production of cytokines, such as IL-17, $\gamma \delta \mathrm{T}$ cells can induce maturation of dendritic cells (DCs) and B cells. Petrasca and Doherty report on the upregulation of the expression of CD86, HLA-DR, IL-6, and TNF $\alpha$ in both DC and B cells upon coculture with human $\mathrm{V} \gamma 9 \mathrm{~V} \delta 2 \mathrm{~T}$ cells, whereas other cytokines, such as IFN $\gamma$ or IL-4, were differentially induced in DC versus B cells (8). Collectively, their data indicate that $\gamma \delta \mathrm{T}$ cells can drive the expression of antigen presenting cell (APC)-associated markers in both DC and B cells (8). Interaction with neighboring cells is a key feature of $\gamma \delta$ T cells. This is particularly true for tissue-resident $\gamma \delta$ T cells. Witherden et al. have reviewed the multiple molecular interactions that have been characterized between skin-resident dendritic epidermal $\gamma \delta \mathrm{T}$ cells and keratinocytes. Among their many effector functions, epidermal $\gamma \delta \mathrm{T}$ cells are involved in wound repair, maintenance of epithelial homeostasis, and protection from malignant transformation (9).

A final aspect of $\gamma \delta \mathrm{T}$ cell differentiation and plasticity is presented in the report of Ziegler et al. (10). These authors made the surprising observation that the small population of human peripheral blood $\mathrm{V} \delta 1 \gamma \delta \mathrm{T}$ cells that simultaneously express CD4, can differentiate into bona fide $\alpha \beta \mathrm{T}$ cells in a process called transdifferentiation. The authors took all measures to avoid the potential contribution of possible artifacts that may influence their results. Their characterization of human $\mathrm{CD} 4^{+} \mathrm{V} \delta 1 \gamma \delta \mathrm{T}$ cells as a source of extrathymic $\mathrm{T}$ cell development challenges current dogmas and opens interesting avenues for future research (10).

\section{Recognition of Pyrophosphate Antigens by Human $\gamma \delta$ T Cells}

A particularly exciting new area of $\gamma \delta \mathrm{T}$ cell research is the role of butyrophilin and butyrophilin-like molecules (which consist of all members of the B7 family of co-stimulators) in $\gamma \delta \mathrm{T}$ cell activation. A member of this family, Skint-1, has been shown as critical for positive selection of mouse $\mathrm{V} \gamma 5 \mathrm{~V} \delta 5$ dendritic epidermal T cells (11). In humans, Butyrophilin 3A1 (BTN3A1) was recently found to play a critical role in the activation of V $\gamma 9 \mathrm{~V} \delta 2 \mathrm{~T}$ cells by pyrophosphate molecules - collectively termed as "phosphoantigens" (pAgs). These intermediates of the eukaryotic mevalonate and the prokaryotic non-mevalonate pathway for isoprenoid synthesis have been identified as specific ligands for the $\mathrm{V} \gamma 9 \mathrm{~V} \delta 2$ TCR that activate this subset of T cells at pico- to nanomolar (microbial pAgs) or micromolar (eukaryotic pAgs) concentrations. The recognition of metabolites that are produced by microbes [e.g., (E)-4-hydroxy-3-methyl-but-2-enyl pyrophosphate (HMBPP)] or that are overproduced by transformed eukaryotic cells [e.g., isopentenyl pyrophosphate (IPP)] provides a formal basis for the role of $\mathrm{V} \gamma 9 \mathrm{~V} \delta 2 \mathrm{~T}$ cells in both anti-infective and anti-tumor immunity (12). Interestingly, the recognition of non-peptidic small molecules is not restricted to human $\gamma \delta$ T cells. As an example, Zeng et al. recently reported that small molecules, such as haptens, are recognized by specific murine $\gamma \delta$ TCRs (13).

For many years, it has been enigmatic how pAgs are actually recognized by the human $\gamma \delta$ TCR, and whether any "presenting" molecules are involved. A major breakthrough was the identification of an agonistic monoclonal antibody (called 20.1) that specifically triggers $\mathrm{V} \gamma 9 \mathrm{~V} \delta 2 \mathrm{~T}$ cell activation among peripheral blood mononuclear cells in a manner that is very similar to pAgs. This antibody is directed against CD277, a member of the B7 superfamily of butyrophilin (BTN) molecules. Detailed studies by Harly et al. identified an indispensable role of the BTN3A1 isoform in the activation of $\mathrm{V} \gamma \mathrm{V} \delta 2 \mathrm{~T}$ cells by pAgs (14). BTN3A1 is a transmembrane molecule with two Ig-like extracellular domains and an intracellular B30.2 domain. This discovery of the essential function of BTN3A1 in $\mathrm{V} \gamma 9 \mathrm{~V} \delta 2 \mathrm{~T}$ cell activation stimulated further research, particularly addressing the question whether BTN3A1 is directly involved in "presenting" pAgs to the $\gamma \delta$ TCR.

In continuation of the above studies, Gennaro de Libero's group has come up with new evidence that suggests the Ig-like extracellular domain of BTN3A1 can directly bind pAgs and that there is specific and direct interaction of soluble V $\gamma 9 \mathrm{~V} \delta 2$ TCR with the BTN3A1-pAg complex (15). Quite surprisingly, however, such a "presenting" function of the extracellular BTN3A1 domain could not be verified by Erin Adam's group. Instead, Adam and colleagues corroborated there being a crucial role of the intracellular B30.2 domain, which may actually directly interact with pAgs (16). In their model, the intracellular B30.2 domain might sense increased levels of intracellular pAgs (due to infection or cellular transformation), possibly inducing a conformational change in the BTN3A1 molecule, which could then be recognized by the V $\gamma 9 \mathrm{~V} \delta 2$ TCR (16). However, the issue appears to be even more complicated. Using $\mathrm{CHO}$ cells reconstituted with chromosome 6 as the only source of human genes, Riaño et al. demonstrate a potential role of other genes on chromosome 6 in addition to BTN3A1 that work to activate human $\mathrm{V} \gamma 9 \mathrm{~V} \delta 2 \mathrm{~T}$ cells (17). The various proponents of the seemingly conflicting models on the capacity of extra- versus intracellular BTN3A1 domains to directly interact with pAgs provide a balanced overview on this controversial issue in this special Research Topic (18-20).

Beyond this, "the intracellular pAg sensing model" recently received additional support from John Trowsdale's group. These authors also reported direct binding of HMBPP to the intracellular B30.2 domain (21). Furthermore, using a yeast-two hybrid screen, theses authors determined that the cytoskeletal protein plakin interacts with the cytoplasmic tail of BTN3A1 in a region proximal to the B30.2 domain. Such protein-protein interactions might be crucial in transmitting signals (e.g., conformational alterations of BTN3A1) from the $\gamma \delta$ TCR upon pAg binding to the intracellular B30.2 domain (21). It is thus evident that many of the mechanistic details of BTN3A1 are still unclear, beyond the undisputed fact that it is indispensable for $\gamma \delta \mathrm{T}$ cell activation by pAgs.

Intriguingly, the mouse lacks BTN3A1 genes and homologous $\gamma \delta$ TCR that would be able to recognize similar pAgs. Karunakaran and Herrmann (22) have studied the ontogenetic evolution of $\mathrm{V} \gamma 9, \mathrm{~V} \delta 2$, and BTN3 genes. Their detailed database analysis suggests that these three genes have co-evolved in placental mammals, while they are lost in rodents and lagomorphs (22). Taken 
together, the controversial issue of the ménage à trois of $\mathrm{V} \gamma 9 \mathrm{~V} \delta 2$ TCR, pAgs, and BTN3A1 awaits additional elucidation. We are grateful that the major players in this particular field have shared their results and thoughtful reflections for this Research Topic.

\section{$\gamma \delta \mathrm{T}$ Cells in Tumor Immunity}

$\gamma \delta \mathrm{T}$ cells can kill a broad range of tumors of epithelial origin as well as many leukemias and lymphomas, and are further able to produce high levels of the anti-tumor cytokine, IFN $\gamma$. Given their HLA non-restricted method of ligand recognition, the role of $\gamma \delta$ $\mathrm{T}$ cells in anti-tumor immunity has stimulated great interest to explore their potential for cancer immunotherapy (23). Interestingly, the production of endogenous pAgs, such as IPP, can be pharmacologically manipulated by nitrogen-containing bisphosphonates (N-BP), which inhibit the downstream processing of IPP, leading to increased levels of endogenous IPP that is sensed by $\mathrm{V} \gamma 9 \mathrm{~V} \delta 2 \mathrm{~T}$ cells (24). Based on this knowledge, intravenous application of the N-BP zoledronate together with low-dose IL2 has been evaluated as a means of in vivo activation of $\gamma \delta$ T cells in cancer patients (25). A recent survey has reviewed the available published studies on the in vivo activation and adoptive transfer of $\gamma \delta$ T cells in cancer patients (26). Most likely, strategies aiming to activate $\gamma \delta$ T cells in vivo will have to be combined with other treatment regimens to obtain optimal anti-tumor activity (27).

In addition to IPP and related pAgs, which serve as antigens for tumor-reactive $\mathrm{V} \gamma 9 \mathrm{~V} \delta 2 \mathrm{~T}$ cells, several cell surface-expressed antigens have been identified for tumor-reactive human non$\mathrm{V} \delta 2 \gamma \delta \mathrm{T}$ cells. One example illustrating the versatility of $\gamma \delta \mathrm{T}$ cells is the endothelial protein $\mathrm{C}$ receptor (EPCR), which is an HLA-related molecule. We (Déchanet-Merville group) identified EPCR as a target for non-V $\delta 2 \gamma \delta \mathrm{T}$ cells that is expressed on endothelial cells infected by cytomegalovirus (CMV) and is also similarly expressed on epithelial tumor cells (28). It is thus conceivable that non-V $\delta 2 \gamma \delta$ T cells have a similar potential for cancer immunotherapy as pAg-reactive V $\delta 2 \mathrm{~T}$ cells $(23,29)$. The recent discovery that CD1d, the closest structural homolog of EPCR, can present self lipids to the human $\mathrm{V} \delta 1 \mathrm{TCR}$, also deserves further investigations in the domain of $\gamma \delta \mathrm{T}$ cell-mediated anti-tumor protection and function $(30,31)$. It should be borne in mind that the anti-tumor efficacy of $\gamma \delta \mathrm{T}$ cell subsets $(\mathrm{V} \gamma 9 \mathrm{~V} \delta 2$, non- $\mathrm{V} \delta 2)$ may, of course, vary between different tumor entities (32).

One of the basic observations supporting a role of immune surveillance in tumor development and progression is the sticking correlation between the proportion of tumor-infiltrating $\mathrm{CD} 3^{+}$ $\mathrm{T}$ cells (TIL) and tumor progression and patient survival (33). $\gamma \delta \mathrm{T}$ cells can represent a significant proportion of $\mathrm{CD}^{+} \mathrm{TIL}$ in different tumors $(34,35)$. Hidalgo et al. analyzed the presence of $\gamma \delta$ T cells among TIL in different types of breast carcinoma. Their results suggest a correlation between higher numbers of $\gamma \delta$ TIL and a better prognosis in medullary breast carcinoma as compared to invasive ductal carcinomas, two subtypes of the Her2- and hormone receptor-negative ("triple-negative") breast carcinoma (35).

It is clear, however, that an increased presence of $\gamma \delta \mathrm{T}$ cells within a tumor per se is not necessarily associated with a beneficial effect. As discussed by Lo Presti et al., there are multiple interactions of tumor-infiltrating $\gamma \delta \mathrm{T}$ cells within the local tumor microenvironment that strongly influence the functional outcome (36). Relevant factors include (but are not restricted to) tumorderived immunosuppressive cytokines, such as TGF- $\beta$, locally expressed inhibitory molecules, such as PD-1, and myeloidderived suppressor cells (MDSCs) located within the tumor stroma (36). Moreover, tumor-infiltrating $\gamma \delta \mathrm{T}$ cells themselves may exert suppressive activity (37) or promote the accumulation of MDSCs (38). Pro-tumoral activity of $\gamma \delta$ T cells has also been demonstrated in several mouse models, and this is mainly mediated through their production of IL-17, which, in these instances, results in the attraction of immunosuppressive myeloid cells and promotion of angiogenesis. Depending on the priming signals in the tumor microenvironment, in addition to other $\gamma \delta \mathrm{T}$ cell subtypes, even pAg-reactive $\mathrm{V} \gamma 9 \mathrm{~V} \delta 2 \mathrm{~T}$ cells may acquire suppressive activity (39). In the context of tumor immunity, multiple scenarios may thus convert $\gamma \delta$ T cells into suppressive cells, which can have counter-productive consequences for tumor immunity (40). Taken together, $\gamma \delta \mathrm{T}$ cells can exert both anti- and protumorigenic activities, and it is a major challenge for future studies to determine how to specifically boost the anti-tumor effects of $\gamma \delta$ T cells while simultaneously shunting their suppressive activity (41). This functional plasticity of mouse and human $\gamma \delta$ T cells in the anti-tumor immune response has been extensively discussed by Lafont et al. (42).

To enhance the anti-tumor activity of $\gamma \delta$ T cells, several strategies are under consideration. These include the use of antibodies to trigger Fc receptor-dependent ADCC, or the use of bispecific antibody constructs to cross-link the $\gamma \delta$ TCR with tumor cell surface antigens. Seidel et al. have explored Fc-optimized antiCD19 antibodies as well as CD19/CD16 bispecific antibodies to enhance $\gamma \delta$ T cell-mediated killing of $\mathrm{CD} 19^{+} \mathrm{B}$ cell malignancies (43). For this purpose, they employed a label-free real-time cytotoxicity assay, which allows monitoring the tumor cell- $\gamma \delta \mathrm{T}$ cell interactions over prolonged periods of time (43). This system was also used by us (Kabelitz group) to demonstrate the efficacy of a Her2-V $\gamma 9$ "tribody" construct in enhancing lysis of Her2expressing pancreatic adenocarcinoma cells by $\mathrm{V} \gamma \rho \mathrm{V} \delta 2$ effector $\mathrm{T}$ cells (34). A different approach to explore the potential use of $\gamma \delta \mathrm{T}$ cells for cancer immunotherapy would be to develop $\gamma \delta \mathrm{T}$ cell-based cancer vaccines. This strategy is based on the seminal discovery of Bernhard Moser's group that found activated human $\mathrm{V} \gamma 9 \mathrm{~V} \delta 2 \mathrm{~T}$ cells may actually serve as "professional" APCs that pick up and process exogenous antigens and load them onto both MHC class II and MHC class I presentation pathways for recognition by $\mathrm{CD}^{+}{ }^{+}$and $\mathrm{CD}^{+} \alpha \beta$ T cells, respectively (44). Toward this end, the capacity of activated human $\gamma \delta$ T cells to take up tumorderived antigens and to present processed peptides to tumor antigen-specific $\mathrm{CD}^{+} \alpha \beta$ T cells has been demonstrated (45). As discussed by Khan et al., the ease with which $\mathrm{V} \gamma 9 \mathrm{~V} \delta 2 \mathrm{~T}$ cells are expanded into large numbers in vitro offers an innovative strategy for the development of $\gamma \delta$ T cell-based tumor vaccines (46).

For the adoptive transfer of in vitro expanded $\gamma \delta \mathrm{T}$ cells, a multitude of experimental protocols have been developed. One important aspect to bear in mind for this procedure is to design means to fully polarize $\gamma \delta$ T cells toward an efficient anti-tumor 
functionality. Promotion of their IFN $\gamma$ expression instead of IL-17 will certainly be an important step toward this aim (41). Along this line, Deniger and coworkers have summarized various strategies of in vitro expansion and further discuss additional perspectives involving genetic approaches to increase the efficacy of $\gamma \delta$ T cellbased immunotherapy (47). A crucial point in this context is the efficient monitoring of $\gamma \delta \mathrm{T}$ cell subpopulations in the blood of cancer patients. We (Kabelitz group) have established a system to accurately determine absolute numbers of circulating $\mathrm{V} \delta 1$ and $\mathrm{V} \delta 2 \gamma \delta \mathrm{T}$ cells from a small sample of whole blood. This method enabled us to determine a threshold number of $\mathrm{V} \delta 2 \mathrm{~T}$ cells per microliter blood below which no cytotoxic activity toward pancreatic adenocarcinoma tumor targets could be triggered by $\mathrm{pAg}$ or Her2-V $\gamma 9$ tribody (48). Another important step for the application of $\gamma \delta$ T cell-based immunotherapy involves identifying the antigenic ligands recognized by $\gamma \delta$ T cells on tumor cells as they may potentially be used as agonistic drugs either ex vivo for $\gamma \delta$ $\mathrm{T}$ cell expansion or in vivo for active vaccination trials. Together, the collection of papers published in this Research Topic discuss critical issues pivotal for understanding the precise role of $\gamma \delta \mathrm{T}$ cells in tumor immunosurveillance or tumor immune evasion as well as highlighting the future potential of $\gamma \delta \mathrm{T}$ cell-based immunotherapies.

\section{$\gamma \delta \mathrm{T}$ Cells in Infection and Other Diseases}

In view of the strong activation of human $\mathrm{V} \gamma 9 \mathrm{~V} \delta 2 \mathrm{~T}$ cells by microbial pAgs (notably HMBPP), it is not surprising to see significant expansion of peripheral blood $\gamma \delta \mathrm{T}$ cells during the acute phase of many infections (49). However, not all microbes produce such $\gamma \delta \mathrm{T}$ cell-stimulating molecules. The differential production of $\gamma \delta \mathrm{T}$ cell ligands by microbes can be used for diagnostic purposes to identify the presence of (mostly Gramnegative) bacteria and thus allow for a pathogen-specific immune fingerprinting. This inventive diagnostic application of $\gamma \delta \mathrm{T}$ cell research in the context of infectious diseases is highlighted in the Opinion Article by Eberl et al. (50).

While $\mathrm{V} \gamma 9 \mathrm{~V} \delta 2 \mathrm{~T}$ cells increase in numbers in many bacterial and parasitic infections, these cells are characteristically reduced in HIV infected individuals. Even upon efficient anti-retroviral therapy and CD4 $\mathrm{T}$ cell reconstitution, $\mathrm{V} \gamma 9 \mathrm{~V} \delta 2 \mathrm{~T}$ cell numbers usually remain low. Pauza and colleagues discuss the potential consequences of persistent low $\mathrm{V} \gamma 9 \mathrm{~V} \delta 2 \mathrm{~T}$ cell numbers in HIV infected individuals and argue in favor of designing innovative clinical trials to reconstitute normal levels of $\mathrm{V} \gamma 9 \mathrm{~V} \delta 2 \mathrm{~T}$ cells (51). Another example of viral infection with high relevance for $\gamma \delta \mathrm{T}$ cells is CMV. Our (Déchanet-Merville group) early studies have

\section{References}

1. Bekiaris V, Sedý JR, Ware CF. Mixing signals: molecular turn ons and turn offs for innate $\gamma \delta$ T-cells. Front Immunol (2014) 5:654. doi:10.3389/fimmu.2014. 00654

2. Ribeiro ST, Ribot JC, Silva-Santos B. Five layers of receptor signaling in $\gamma \delta$ T-cell differentiation and activation. Front Immunol (2015) 6:15. doi:10.3389/fimmu. 2015.00015

3. Cua DJ, Tato CM. Innate IL-17-producing cells: the sentinels of the immune system. Nat Rev Immunol (2010) 10:479-89. doi:10.1038/nri2800 uncovered a remarkable expansion of $\mathrm{V} \delta 2$-negative $\gamma \delta \mathrm{T}$ cells in CMV-positive but not -negative kidney transplant recipients (52). Further studies have revealed multiple possible functions of CMV-induced $\gamma \delta \mathrm{T}$ cells, including direct anti-viral activity. Concomitant studies in mouse models point to a protective role of murine $\gamma \delta \mathrm{T}$ cells against CMV infection $(53,54)$. All these aspects including the cross-reactivity of CMV-reactive non- $\mathrm{V} \delta 2$ $\gamma \delta$ T cells with certain epithelial tumor entities are discussed in a review article by Couzi et al. (55).

This Research Topic also addresses the role of $\gamma \delta \mathrm{T}$ cells in non-infectious diseases. In addition to infection and cancer, autoimmune diseases, and wound healing and burn injuries have been addressed by Latha et al. (56). This review summarizes the extensive evidence showing the involvement of $\gamma \delta$ T cells in many pathophysiological conditions. An interesting specific example is reported by Marcu-Malina and coworkers (57) who observed a TNF-dependent induction of procoagulant tissue factor-1 (TF-1) in monocytes by zoledronate-stimulated $\gamma \delta$ T cells. This seemed to occur specifically in $\gamma \delta$ T cells from patients with systemic sclerosis (57). Last but not least, this Research Topic additionally covers the role of $\gamma \delta$ T cells in the diagnosis of immunodeficiencies. TCR immunodeficiencies can affect both $\alpha \beta$ and $\gamma \delta$ T cells. While $\alpha \beta$ $\mathrm{T}$ cells have been extensively studied, $\gamma \delta \mathrm{T}$ cells are frequently ignored, partly due to their numerical scarcity in circulation. Garcillán et al. discuss these issues in detail and present a useful diagnostic flowchart (58).

\section{Concluding Remarks}

After 30 years of $\gamma \delta \mathrm{T}$ cell research, it is clear that these cells are intimately involved in the control of tissue homeostasis, infection, and malignancy. The identification of specific ligands for the $\gamma \delta$ TCR provides strong support for the idea that $\gamma \delta$ T cells are non-redundant to $\alpha \beta \mathrm{T}$ cells. Apart from the detailed knowledge of their physiological and pathophysiological significance, we are currently experiencing new exciting developments aimed at bringing $\gamma \delta \mathrm{T}$ cells into clinical medicine.

\section{Acknowledgments}

We are grateful to all our colleagues for their contribution to this Research Topic. Thanks to all of them, this collection of papers provides a state-of-the-art overview of the current knowledge and insight into "hot topics" of on-going $\gamma \delta \mathrm{T}$ cell research. Special thanks are due to Dr. Shirin Kalyan for critically reading the manuscript.

4. Prinz I, Sansoni A, Kissenpfennig A, Ardouin L, Malissen M, Malissen B. Visualization of the earliest steps of gammadelta $\mathrm{T}$ cell development in the adult thymus. Nat Immunol (2006) 7:995-1003. doi:10.1038/ ni1371

5. Haas JD, Ravens S, Dübner S, Sandrock I, Oberdörfer L, Kashani E, et al. Development of interleukin-17-producing $\gamma \delta \mathrm{T}$ cells is restricted to a functional embryonic wave. Immunity (2012) 37:48-59. doi:10.1016/j.immuni.2012. 06.003

6. Wei YL, Han A, Glanville J, Fang F, Zuniga LA, Lee JS, et al. A highly focused antigen receptor repertoire characterizes $\gamma \delta \mathrm{T}$ cells that are poisoned to make 
IL-17 rapidly in naive animals. Front Immunol (2015) 6:118. doi:10.3389/fimmu. 2015.00118

7. Patil RS, Bhat SA, Dar AA, Chiplunkar SV. The Jekyll and Hyde story of IL17producing $\gamma \delta \mathrm{T}$ cells. Front Immunol (2015) 6:37. doi:10.3389/fimmu.2015. 00037

8. Petrasca A, Doherty DG. Human $V \delta 2^{+} \gamma \delta \mathrm{T}$ cells differentially induce maturation, cytokine production and alloreactive $\mathrm{T}$ cell stimulation by dendritic cells and B cells. Front Immunol (2014) 5:650. doi:10.3389/fimmu. 2014.00650

9. Witherden DA, Ramirez K, Havran WL. Multiple receptor-ligand interactions direct tissue-resident $\gamma \delta \mathrm{T}$ cell activation. Front Immunol (2014) 5:602. doi:10. 3389/fimmu.2014/00602

10. Ziegler H, Welker C, Sterk M, Haarer J, Rammensee HG, Handgretinger R, et al. Human peripheral $\mathrm{CD} 4^{+} \mathrm{V} \delta 1^{+} \gamma \delta \mathrm{T}$ cells can develop into $\alpha \beta \mathrm{T}$ cells. Front Immunol (2014) 5:645. doi:10.3389/fimmu.2014.00645

11. Lewis JM, Girardi M, Roberts SJ, Barbee SD, Hayday AC, Tigelaar RE. Selection of the cutaneous intraepithelial $\gamma \delta+\mathrm{T}$ cell repertoire by a thymic stromal determinant. Nat Immunol (2006) 7:843-50. doi:10.1038/ni1363

12. Kalyan S, Kabelitz D. Defining the nature of human $\gamma \delta \mathrm{T}$ cells: a biographical sketch of the highly empathetic. Cell Mol Immunol (2013) 10:21-9. doi:10.1038/ cmi.2012.44

13. Zeng X, Meyer C, Huang J, Newell EW, Kidd BA, Wei YL, et al. Gamma delta $\mathrm{T}$ cells recognize haptens and mount a hapten-specific response. ELife (2014) 3:e03609. doi:10.7554/eLife.03609

14. Harly C, Guillaume Y, Nedellec S, Peigné CM, Mönkkönen H, Mönkkönen J, et al. Key implication of CD277/butyrophilin-3 (BTN3A) in cellular stress sensing by a major human $\gamma \delta$ T-cell subset. Blood (2012) 120:2269-79. doi:10. 1182/blood-2012-05-430470

15. Vavassori S, Kumar A, Wan GS, Ramanjaneyulu GS, Cavallari M, El Daker S, et al. Butyrophilin 3A1 binds phosphorylated antigens and stimulates human $\gamma \delta$ T cells. Nat Immunol (2013) 14:908-16. doi:10.1038/ni.2665

16. Sandstrom A, Peigné CM, Léger A, Crooks JE, Konczak F, Gesnel MC, et al. The intracellular B30.2 domain of butyrophilin 3A1 binds phosphoantigens to mediate activation of human $\mathrm{V} \gamma 9 \mathrm{~V} \delta 2 \mathrm{~T}$ cells. Immunity (2014) 40:490-500. doi:10.1016/j.immuni.2014.03.003

17. Riaño F, Karunakaran MM, Starick L, Li J, Scholz CJ, Kunzmann V, et al. $\mathrm{V} \gamma 9 \mathrm{~V} \delta 2 \mathrm{TCR}$-activation by phosphorylated antigens requires butyrophilin $3 \mathrm{~A}$ 1 (BTN3A1) and additional genes on human chromosome 6. Eur J Immunol (2014) 44:2571-6. doi:10.1002/eji.20144712

18. De Libero G, Lau SY, Mori L. Phosphoantigen presentation to TCR $\gamma \delta$ T cells, a coundrum getting less gray zones. Front Immunol (2015) 5:679. doi:10.3389/ fimmu.2014.00679

19. Gu S, Nawrocka W, Adams EJ. Sensing pyrophosphate metabolites by V $\gamma 9 \mathrm{~V} \delta 2$ T cells. Front Immunol (2015) 5:688. doi:10.3389/fimmu.2014.00688

20. Harly C, Peigné CM, Scotet E. Molecules and mechanisms implicated in the peculiar antigenic activation process of human $\mathrm{V} \gamma 9 \mathrm{~V} \delta 2 \mathrm{~T}$ cells. Front Immunol (2015) 5:657. doi:10.3389/fimmu.2014.00657

21. Rhodes DA, Chen HC, Price AJ, Keeble AH, Davey MS, James LC, et al. Activation of human $\gamma \delta \mathrm{T}$ cells by cytosolic interactions of BTN3A1 with soluble phosphoantigens and the cytoskeletal adaptor protein periplakin. J Immunol (2015) 194:2390-8. doi:10.4049/jimmunol.1401064

22. Karunakaran MM, Herrmann T. The $\mathrm{V} \gamma 9 \mathrm{~V} \delta 2 \mathrm{~T}$ cell antigen receptor and butyrophilin-3 A1: models of interaction, the possibility of co-evolution, and the case of dendritic epidermal T cells. Front Immunol (2014) 5:648. doi:10.3389/ fimmu.2014.00648

23. Kabelitz D, Kalyan S, Oberg HH, Wesch D. Human V $\delta 2$ versus non-V $\delta 2 \gamma \delta \mathrm{T}$ cells in antitumor immunity. Oncoimmunology (2013) 3:e23304. doi:10.4161/ onci. 23304

24. Gober HJ, Kistowska M, Angman L, Jenö P, Mori L, de Libero G. Human T cell receptor $\gamma \delta$ cells recognize endogenous mevalonate metabolites in tumor cells. J Exp Med (2003) 197:163-8. doi:10.1084/jem.20021500

25. Dieli F, Vermijlen D, Fulfaro F, Caccamo N, Meraviglia S, Cicero G, et al. Targeting human $\gamma \delta$ T cells with zoledronate and interleukin-2 for immunotherapy of hormone-refractory prostate cancer. Cancer Res (2007) 67:7450-7. doi:10.1158/ 0008-5472-CAN-07-0199

26. Fisher JP, Heuijerjans J, Yan M, Gustafsson K, Anderson J. $\gamma \delta$ T cells for cancer immunotherapy: a systematic review of clinical trials. Oncoimmunology (2014) 3:e27572. doi:10.4161/onci.27572
27. Poggi A, Zocchi MR. $\gamma \delta$ T lymphocytes as a first line of immune defense: old and new ways of antigen recognition and implications for cancer immunotherapy. Front Immunol (2014) 5:575. doi:10.3389/fimmu.2014.00575

28. Willcox CR, Pitard V, Netzer S, Couzi L, Salim M, Moreau JF, et al. Cytomegalovirus and tumor stress surveillance by binding of a human $\gamma \delta \mathrm{T}$ cell antigen receptor to endothelial protein C receptor. Nat Immunol (2012) 13:872-9. doi:10.1038/ni.2394

29. Fisher J, Kramer AM, Gustafsson K, Anderson J. Non-V $\delta 2 \gamma \delta$ T lymphocytes as effectors of cancer immunotherapy. Oncoimmunology (2014) 4:e973808. doi:10. 4161/2162402X.2014.973808

30. Luoma AM, Castro CD, Mayassi T, Bembinster LA, Bai L, Picard D, et al. Crystal structure of $\mathrm{V} \delta 1 \mathrm{~T}$ cell receptor in complex with CD1d-sulfatide shows MHC-like recognition of a self-lipid by human $\gamma \delta \mathrm{T}$ cells. Immunity (2013) 39:1032-42. doi:10.1016/j.immuni.2013.11.001

31. Uldrich AP, Le Nours J, Pellicci DG, Gherardin NA, McPherson KG, Lim RT, et al. CD1d-lipid antigen recognition by the $\gamma \delta$ TCR. Nat Immunol (2013) 14:1137-45. doi:10.1038/ni.2713

32. Scheper W, Sebestyen Z, Kuball J. Cancer immunotherapy using $\gamma \delta \mathrm{T}$ cells: dealing with diversity. Front Immunol (2014) 5:601. doi:10.3389/fimmu.2014. 00601

33. Galon J, Costes A, Sanchez-Cabo F, Kirilovsky A, Mlecnik B, Lagorce-Pagès C. Type, density, and location of immune cells within human colorectal tumors predict clinical outcome. Science (2006) 313:1960-4. doi:10.1126/ science.1129139

34. Oberg HH, Peipp M, Kellner C, Sebens S, Krause S, Petrick D, et al. Novel bispecific antibodies increase $\gamma \delta$ T-cell cytotoxicity against pancreatic cancer cells. Cancer Res (2014) 74:1349-60. doi:10.1158/0008-5472.CAN-13-0675

35. Hidalgo JV, Bronsert P, Orlowska-Volk M, Díaz LB, Stickeler E, Werner M, et al. Histological analysis of $\gamma \delta \mathrm{T}$ lymphocytes infiltrating human triplenegative breast carcinomas. Front Immunol (2014) 5:632. doi:10.3389/fimmu. 2014.00632

36. Lo Presti E, Dieli F, Meraviglia S. Tumor-infiltrating $\gamma \delta$ T lymphocytes: pathogenic role, clinical significance, and differential programming in the tumor microenvironment. Front Immunol (2014) 5:607. doi:10.3389/fimmu. 2014.00607

37. Peng G, Wang HY, Peng W, Kiniwa Y, Seo KH, Wang RF. Tumor-infiltrating gammadelta $\mathrm{T}$ cells suppress $\mathrm{T}$ and dendritic cell functions via mechanisms controlled by a unique toll-like receptor signaling pathway. Immunity (2007) 27:334-48. doi:10.1016/j.immuni.2007.05.020

38. Wu P, Wu D, Ni C, Ye J, Chen W, Hu G, et al. $\gamma \delta \mathrm{T} 17$ cells promote the accumulation and expansion of myeloid-derived suppressor cells in human colorectal cancer. Immunity (2015) 40:785-800. doi:10.1016/j.immuni.2014.03.013

39. Kabelitz D, Peters C, Wesch D, Oberg HH. Regulatory functions of gammadelta T cells. Int Immunopharmacol (2013) 16:382-7. doi:10.1016/j.intimp. 2013.01.022

40. Wesch D, Peters C, Siegers GM. Human gamma delta T regulatory cells in cancer: fact or fiction? Front Immunol (2014) 5:598. doi:10.3389/fimmu.2014. 00598

41. Rei M, Pennington DJ, Silva-Santos B. The emerging protumor role of $\gamma \delta$ T lymphocytes: implications for cancer immunotherapy. Cancer Res (2015) 75:798-802. doi:10.1158/0008-5472.CAN-14-3228

42. Lafont V, Sanchez F, Laprevotte E, Michaud HA, Gros L, Eliaou JF, et al. Plasticity of $\gamma \delta \mathrm{T}$ cells: impact on the anti-tumor response. Front Immunol (2014) 5:622. doi:10.3389/fimmu.2014.00622

43. Seidel UJE, Vogt F, Grosse-Hovest L, Jung G, Handgretinger R, Lang P. $\gamma \delta \mathrm{T}$ cell-mediated antibody-dependent cellular cytotoxicity with CD19 antibodies assessed by an impedance-based label-free real-time cytotoxicity assay. Front Immunol (2014) 5:618. doi:10.3389/fimmu.2014.00618

44. Brandes M, Willimann K, Moser B. Professional antigen-presentation function by human gammadelta T cells. Science (2005) 309:264-8. doi:10.1126/science. 1110267

45. Himoudi N, Morgenstern DA, Yan M, Vernay B, Saraiva L, Wu Y, et al. Human $\gamma \delta$ T lymphocytes are licensed for professional antigen presentation by interaction with opsonized target cells. J Immunol (2012) 188:1708-16. doi:10.4049/jimmunol.1102654

46. Khan MWA, Eberl M, Moser B. Potential use of $\gamma \delta \mathrm{T}$ cell-based vaccines in cancer immunotherapy. Front Immunol (2014) 5:512. doi:10.3389/fimmu.2014. 00512 
47. Deniger DC, Moyes JS, Cooper LJN. Clinical applications of gamma/delta T cells with multivalent immunity. Front Immunol (2014) 5:636. doi:10.3389/ fimmu.2014.00636

48. Oberg HH, Kellner C, Peipp M, Sebens S, Adam-Klages S, Gramatzki M, et al. Monitoring circulating $\gamma \delta \mathrm{T}$ cells in cancer patients to optimize $\gamma \delta$ T cell-based immunotherapy. Front Immunol (2014) 5:643. doi:10.3389/fimmu. 2014.00643

49. Ness-Schwickerath KJ, Morita CT. Regulation and function of IL-17A- and IL-22-producing $\gamma \delta$ T cells. Cell Mol Life Sci (2011) 68:2371-90. doi:10.1007/ s00018-011-0700-z

50. Eberl M, Friberg IM, Liuzzi AR, Morgan MP, Topley N. Pathogen-specific immune fingerprints during acute infection: the diagnostic potential of human $\gamma \delta$ T-cells. Front Immunol (2014) 5:572. doi:10.3389/fimmu.2014.00572

51. Pauza CD, Poonia B, Li H, Cairo C, Chaudhry S. $\gamma \delta$ T cells in HIV disease: past, present, and future. Front Immunol (2015) 5:687. doi:10.3389/fimmu.2014. 00687

52. Déchanet-Merville J, Merville P, Lim A, Retière C, Pitard V, Lafarge X, et al. Implication of $\gamma \delta \mathrm{T}$ cells in the human immune response to cytomegalovirus. J Clin Invest (1999) 103:1437-49. doi:10.1172/JCI5409

53. Khairallah C, Netzer S, Villacreces A, Juzan M, Rousseau B, Dulanto S, et al. $\gamma \delta \mathrm{T}$ cells confer protection against murine cytomegalovirus (MCMV). PLoS Pathog (2015) 11:e1004702. doi:10.1371/journal.ppat.1004702

54. Sell S, Dietz M, Schneider A, Holtappels R, Mach M, Winkler TH. Control of murine cytomegalovirus infection by $\gamma \delta$ T cells. PLoS Pathog (2015) 11:e1004481. doi:10.1371/journal.ppat.1004481
55. Couzi L, Pitard V, Moreau JF, Déchanet-Merville J. Direct and indirect effects of cytomegalovirus-induced $\gamma \delta \mathrm{T}$ cells after kidney transplantation. Front Immunol (2015) 6:3. doi:10.3389/fimmu.2015.00003

56. Latha TS, Reddy MC, Durbaka PVR, Rachamallu A, Pallu R, Lomada D. $\gamma \delta \mathrm{T}$ cell-mediated immune responses in disease and therapy. Front Immunol (2014) 5:571. doi:10.3389/fimmu.2014.00571

57. Marcu-Malina V, Balbir-Gurman A, Dardik R, Braun-Moscovici Y, Segel MJ, Bank I. A novel prothrombotic pathway in systemic sclerosis patients: possible role of bisphosphonate-activated $\gamma \delta$ T cells. Front Immunol (2014) 5:414. doi:10. 3389/fimmu.2014.00414

58. Garcillán B, Marin AVM, Jiménez-Reinoso A, Briones AC, Muñoz-Ruiz M, García-León MJ, et al. $\gamma \delta \mathrm{T}$ lymphocytes in the diagnosis of human $\mathrm{T}$ cell receptor immunodeficiencies. Front Immunol (2015) 6:20. doi:10.3389/fimmu. 2015.00020

Conflict of Interest Statement: The authors declare that the research was conducted in the absence of any commercial or financial relationships that could be construed as a potential conflict of interest.

Copyright (C) 2015 Kabelitz and Déchanet-Merville. This is an open-access article distributed under the terms of the Creative Commons Attribution License (CC BY). The use, distribution or reproduction in other forums is permitted, provided the original author(s) or licensor are credited and that the original publication in this journal is cited, in accordance with accepted academic practice. No use, distribution or reproduction is permitted which does not comply with these terms. 